Sonja Vandermeeren*

\title{
German language needs in Danish companies
}

\begin{abstract}
The first section of my paper provides a definition of the need for foreign languages in the business context and catalogues types and indicators of this need. In the second section the methods that can be employed in needs analysis studies are presented. Section three provides illustrative material from a questionnaire-based pilot survey. Taking the case of German companies, I investigate their expectations with regard to linguistic and cultural adaptation by their Danish business partners. Contrary to expectation, knowledge of German culture is regarded as more useful than German language knowledge. The educational implications of the findings of needs analysis studies are then dealt with in the fourth section.
\end{abstract}

\section{Definition and types of foreign language needs in companies}

The need of companies for foreign languages has many facets: phonetic/ orthographical, lexical, grammatical, pragmatic and cultural. Not only linguistic but also cultural adaptation is a vehicle for commerce and preventive of miscommunication in international business interactions. Because of the close relationship between language and culture the need for foreign language competence unequivocally has a cultural aspect, which is mirrored by my definition. I propose defining this need in the following way:

A need of business firms for employees with sufficient knowledge of foreign languages and of the cultures in which these languages are embedded; sufficient in the sense that it will allow the company to initiate and consolidate business relations with speakers of these languages (Vandermeeren 1998: 60).

\footnotetext{
* Sonja Vandermeeren

Germanistisches Seminar der Universität Kiel

Olshausenstraße 40-60

D-24098 Kiel

vandermeeren@germsem.uni-kiel.de
} 
14

I differentiate between the following five types of needs (Vandermeeren 1998: 70-71):

- objective need (indicated by objective need indicators, e.g. turnover in a certain market),

- subjective need (indicated by subjective informant's perceptions of foreign language need),

- unconscious need (indicated by the subtraction of subjective need from objective need),

- subjective unmet need (indicated by informants' perceptions of unmet foreign language need),

- objective unmet need (indicated by the subtraction of foreign language use from objective need).

Empirical data on various indicators of these five distinct kinds of needs, taken together, enable us to look at the foreign language needs of business firms in great detail. To exemplify some indicators:

- objective need: e.g. frequency of business interactions with foreign business environments;

- subjective need: e.g. top managers' ideal of

- how competent their staff should be in a certain foreign language;

- how aware their staff should be of the socio-cultural context of that language;

- unconscious need: e.g. sales managers' claim that their department does not need employees competent in a certain foreign language although it is in regular business contact with speakers of that language;

- subjective unmet need:

- e.g. secretaries' reports of the difficulties they encounter when using a certain foreign language orally or in writing;

- e.g. middle management's statement that cultural barriers prevent joint ventures with companies in foreign countries from becoming successful;

- objective unmet need: e.g. export managers' statement that their department does not use a certain foreign language although it has regular business relations with speakers of that language. 
Language needs have two dimensions. The quantitative dimension is revealed by asking how often the foreign language under investigation is needed. The qualitative dimension is revealed by the question "Which kind of competence in this language is needed?". Answers to these questions can be obtained from various informants, for instance from top managers, sales managers, sales employees, lecturers in intercultural communication, etc. To my knowledge it has never been attempted to interview the native speakers involved, that is foreign business partners.

\section{Methods in language needs research}

The research techniques that can be used in investigations of language needs are manifold: observation, interview, questionnaire, language test, etc. In this section I will describe the most important ones.

One of the indicators of language need, namely language usage, is directly observable. To prevent the target persons from concealing their communicative practices from the researcher, the latter collects data incognito in a natural situation or gathers 'naturalistic' data experimentally. Van Hest and Oud (1990) mention that the Scottish Association for Language Teaching instigated a participant observation of people working in the Scottish tourism sector. Germans, Frenchmen, Spaniards, etc. living in the United Kingdom pretended to be tourists in face-to-face interaction with this target group to be able to assess their foreign language skills. By participant observation the most naturalistic data are collected, but it is an extremely time-consuming method, especially when the goal is statistical representativeness. Moreover, we must remember that we are dealing with researchers' perceptions (of for instance language competence), which do not necessarily reflect the objective reality.

Interviews and (postal) questionnaires serve to present informants with open or closed questions about their (or others') language needs. Closed questions are easier to analyze and to score than open questions. In structured interviews, researchers go through a questionnaire with the informants to allow them to explain and differentiate their answers. A rapid way of investigating language needs is provided by scaling techniques, which can easily discriminate among respondents with different opinions. Subjects are asked to agree or disagree with negative and positive items (e.g. agree strongly, agree, undecided, disagree and disagree strongly). A large proportion of (social) psychological literature is devoted to the 
danger of response bias caused by this type of questionnaires. There is considerable discussion of the possibility that respondents may generally be more inclined to acquiesce in a statement than to disagree with it (Schuman \& Presser 1981: 203-205). Questionnaire-based surveys (Verdoodt \& Delbeke 1983, Dannerer 1992, Grinsted 1993, Vandermeeren 1998) only give access to informants' real perceptions of language need when they are carried out with extreme methodological care. If questionnaires are sent to companies, a lot of persuasive work has to be done as well. The informants must be persuaded to complete the questionnaire in order to avoid low response rates.

To shed additional light on the foreign language needs of companies, their newspaper job advertisements, which mention the foreign language skills required at recruitment, can be analyzed (Drochner \& Kirchberg 1987, Glück 1992). These analyses are not entirely in accordance with the actual situation, as there are a number of positions where foreign languages are tacitly required, and sometimes the position to be filled does not really require the foreign language skills mentioned, but mentioning them is good for PR reasons.

Language tests are educational tools which are used in the second stage of corporate language audits. The four stages of an audit are as follows:

- identification of foreign language skills required of employees to complete their communication tasks,

- determination of the foreign language proficiency of the employees,

- comparison of the existing level of command with the required level and

- proposal for the educational language policies to be adopted by the company to improve the foreign language proficiency of its employees.

Language tests yield qualitative information on language skills. Fishman and Cooper (1978) recommend communicative tests which expose subjects to contextualized linguistic input, drawing on real-life situations. Three questions arise: "Which job situations are relevant?", "How can they be built into the tests?" and "Can the output be assessed in an objective way?" (Van Els et al. 1984: 312-332). 
The Delphi-method gathers information from specialist informants who are repeatedly asked to fill out the same questionnaire anonymously. The respondents, who are in disagreement at first, are given access to the perceptions of their fellow respondents and interviewed further until a general consensus is reached (Atteslander 1993: 172). Martin and Chaney (1992) relied on this method to develop an optimum curriculum for students of intercultural business communication. They used the following respondents: business persons who are faced with cross-cultural communication as part of their job, lecturers in intercultural communication and members of the Academy of International Business (AIB).

\section{Illustrative material from a pilot survey}

The concept "foreign language needs" provides the theoretical starting point for a pilot survey that was conducted in Northern Germany, SchleswigHolstein to be exact. It is operationalized in the form of a questionnaire that elicits information on two types of language need, namely subjective need and subjective unmet need. It sheds light on a so far little-investigated factor which shapes foreign language need, namely the attitudes of native speakers towards linguistic and cultural adaptation on the part of their non-native communication partners. Taking the case of SchleswigHolsteinian companies, I investigate their expectations with regard to the linguistic and cultural adaptation by their (Danish) business partners. In other words, I primarily look at qualitative language needs as perceived by native speakers by attempting to answer the following questions:

- "Do German companies consider it necessary for their (Danish) business partners to use German?",

- "Which level of German language command do Germans consider as a prerequisite for successful communication?",

- "Do Germans stress the need for their (Danish) communication partners to follow German socio-cultural norms?".

A four-page questionnaire containing only closed questions was formulated for this pilot survey in the federal state of Schleswig-Holstein and sent to 50 companies (in its five largest cities ${ }^{1}$ ) registered in the

1 Kiel, Lübeck, Flensburg, Neumünster and Norderstedt 
"ABC der deutschen Wirtschaft" online data base as exporting firms and employing more than 25 persons. After one mail-shot, 9 of them had replied. I telephoned the remaining companies to have them complete the questionnaire if possible. Eventually, the rejection rate was very low. A total of 34 firms (68\%) filled out the first two pages of the questionnaire. 25 of these also completed the last two pages, only intended for companies with business connections to Denmark.

First, let us explore the issue of linguistic adaptation. How did the responding companies evaluate foreign firms' use of German? The answer was given on a 6 -point rating scale $(1=$ very positively and $6=$ very negatively). An averaged answer of 2.5 was obtained. A standard deviation of 0.9 indicates that the respondents are almost in agreement. Most of them have a moderately positive attitude to the use of German by their foreign business partners.

How did the respondents rate foreign firms' use of German in terms of usefulness ( $1=$ very purposeful and $6=$ totally unnecessary)? An average of the answers was calculated separately for each of the following communication tasks:

- invoice $($ mean $=3.4)$,

- offer (3.3),

- acknowledgment of order (3.3),

- inquiry (3.2),

- $\operatorname{order}(3.2)$,

- complaint concerning delay (3.1),

- explanation of delay (3.1),

- $\operatorname{small}$ talk (3.1),

- company depiction (3.0),

- self-introduction ${ }^{2}(2.9)$,

- price/conditions negotiation (2.9) and

- product depiction (2.8).

These results suggest that Schleswig-Holsteinian companies rate the use of German less favorably on the usefulness dimension than in a general evaluation. They have a barely favorable attitude to the usefulness of

2 education/position with the company 
German for their foreign business partners, almost regardless of the communication task or the communicator. They even seem to think that it does not make more sense for their suppliers to use German (when writing pre-sale documents such as offers) than for their customers (when writing documents such as orders).

The third question measured the respondents' attitudes to limited German language command. The companies which responded to the questionnaire evaluate incorrect German language usage in business letters sent to German companies by foreign companies as not really annoying ( $1=$ very annoying, $6=$ not annoying at all). Ungrammatical word forms (e.g. wrong declension) (4.7) and incorrect spelling (4.7) score only very slightly higher than inexact wording (wrong word (4.3)/sentence construction (4.5)) and unsuitable style (e.g. too formal/not formal enough) (4.4).

One can deduce from the answers to the next question that German companies regard knowledge of German culture as more useful than German language knowledge (a difference of up to 1.5 points). Knowledge of German corporate culture is viewed as most useful:

- knowledge of German corporate culture ${ }^{3}$ (1.8),

- knowledge of organizational structure of German companies ${ }^{4}(2.4)$,

- knowledge of German cultural norms and customs (2.4)

- knowledge of economic geography of Germany ${ }^{5}(2.5)$

- knowledge of German politics (2.9).

Respondents also indicated their level of agreement with the following statements concerning linguistic and cultural adaptation on a scale from 1 (strongly agree) to 6 (strongly disagree):

- Knowledge of English suffices for initiating and securing business connections to German companies (2.4);

- Command of German is a prerequisite for initiating and securing business connections to German companies (4.3);

\footnotetext{
3 negotiating/managerial culture, etc.

4 departments/company hierarchy

5 locations and imported/exported articles
} 
- Foreign firms should follow their own cultural norms as closely as possible in communication with German companies (3.5);

- Foreign firms should follow German cultural norms as closely as possible in communication with German companies (3.2);

- Foreign firms should follow German cultural norms and simultaneously show their own cultural identity in communication with German companies (2.2).

Schleswig-Holsteinian firms see only a little advantage in their business partners using German. More emphasis was placed on cultural adaptation. However, they endorse cultural adaptation unequivocally only when it is not too strong, i.e. when communication partners also show their own cultural identity. Among American business people Francis (1991: 409) found similar preference for moderate cultural adaptation on the part of their Japanese business partners.

Let us now turn to the questions relevant to Schleswig-Holsteinian firms exporting to Denmark ( 25 respondents). Question number 6 read: "How do you evaluate the following mistakes in the language usage of Danish company representatives speaking German in a poor but still intelligible manner to German company representatives?" (1=very annoying, $6=$ not annoying at all). The results of this rating task are as follows: incorrect pronunciation made a score of 5.2, ungrammatical word forms a score of 5.1, wrong sentence construction 5.0, wrong word 4.7 and unsuitable style (e.g. too formal/not formal enough) 4.0.

These ratings are higher than the ones elicited by the third question dealing with mistakes in the language usage of foreign company representatives writing business letters in German. Apparently the respondents evaluate mistakes differently in the spoken and written modes. The replies indicate that poorly spoken German is considered less annoying than poorly written German.

Danes are believed to have a fairly solid command of German, as shown by the level of respondent agreement with the first two statements on the following list $(1=$ strongly agree and $6=$ strongly disagree $)$ :

- Danish company representatives usually have good written proficiency in German (2.7);

- They usually have good oral proficiency in German (1.9);

- They usually have good knowledge of German culture (2.6); 
- They have an incorrect view of German culture (4.6);

- They follow their own cultural norms in communication with German company representatives (3.6);

- They act insufficiently according to German cultural norms in communication with German company representatives (4.4);

- English is too often chosen by Danish companies in communication with German firms (4.4)

- Language barriers between Germany and Denmark complicate the establishment and maintenance of German-Danish business contacts (4.2);

- Cultural barriers between Germany and Denmark complicate the establishment and maintenance of German-Danish business contacts (5.1).

These ratings indicate that the respondents believe Danish company representatives to be competent German speakers whose written command of German and their knowledge of German culture could be improved. Moderately positive attitudes towards the use of English as a lingua franca were expressed. This finding raises the point of actual English language use frequency. How often do Danish companies actually choose English in communication with German firms? Rasmussen (2000) reports that of the 85 Danish company representatives in her sample, $91 \%$ stated that they used German (44\% solely and $47 \%$ in combination with English). Likewise, Grinsted (1993) found that of the 297 Danish companies in her sample, $87 \%$ used German. $75 \%$ saw a need for German language proficiency and about $10 \%$ admitted to having an unmet German language need.

Through their answers to the last two statements on the list, my Schleswig-Holsteinian respondents show moderate disagreement with the contention that language and cultural barriers complicate the initiating of business relations between Germany and Denmark. Moreover, they seem to think that business connections are less frequently impaired by cultural barriers than by language barriers.

To what extent do Danish company representatives - in the respondents' opinion - follow German cultural norms in communication with German firms ( $1=$ to a fully sufficient extent and $6=$ to an entirely insufficient extent)? 4 to 7 of the 25 respondents do not consider it necessary for 
22

Danes to adapt to the German cultural norms mentioned in the questionnaire. The remaining respondents indicated to what extent Danish company representatives follow these cultural norms. Their replies range between 2.5 and 2.9 on average:

- German way of speaking to one another (5) (2.5),

- German sense of humor (7) (2.9),

- German way of keeping one's distance (4) (2.8) and

- German way of addressing one another (e.g. "Sie" versus "du") (6) (2.6).

A previously-cited study (Rasmussen 2000: 121) found cases of asymmetrical addressing in telephone conversations between Danish and German company representatives (one communication partner using "Sie", the other "du"). The communication partners, however, did not use those different forms of address consistently. Rasmussen points out that symmetrical addressing is tacitly negotiated during the course of the conversation.

Let us turn to the next item in the questionnaire. To what extent do Danish company representatives - in the respondents' opinion - display the following ways of behaving $(1=$ to a fully sufficient extent and $6=$ to an entirely insufficient extent)? (The answer "I do not consider it necessary for them to display this behavior" was not ticked off):

- carefully preparing business contacts (2.1),

- handing on information inside the Danish company (2.7),

- informing German business partners (2.7),

- informing German business partners in writing rather than by telephone (3.4),

- writing acknowledgments of order (2.6),

- respecting German company hierarchy (2.1),

- keeping private and business matters separate (2.2),

- engaging in small talk before business matters are discussed (2.2),

- dressing appropriately (2.1).

One can deduce from the answers that - in the opinion of Germans - the written mode of Danish corporate language use receives short thrift. It is 
not viewed as appropriate to hand on information to other companies primarily by telephone.

Similar unmet expectations were found by Pogner (1999: 113-114), who examined how the Municipal Services of Wendenburg (in the eastern part of Germany) responded to an Energy Concept document written for their town by a group of Danish engineers. In the follow-up interviews the Danes attributed the fact that the document did not entirely live up to German expectations to the factor "differences between the German and the Danish culture". The stereotypical topos on over-thorough, overformal and over-bureaucratic Germany was repeatedly mentioned. While, from the point of view of the Danish engineers, German thoroughness causes unnecessary complications, it also has the positive effect that more emphasis is placed on written documents than is the case in Denmark.

In the international business environment, communication partners are exposed to reciprocal stereotyped views of each other. Typically, investigations of stereotyping link together traits assigned to stereotyped persons by the surveyed persons and their evaluation of these traits. In the present study the answers to the following two questions link up to suggest how German company representatives see their Danish counterparts: "How do Schleswig-Holsteinian firms characterize Danish company representatives?" and "Are these characteristics valued by the surveyed persons?". Among the respondents I found some evaluative preference for the following traits $(1=$ very positive and $6=$ very negative): hospitality (1.7), punctuality (1.7), discipline (1.8), tolerance (1.9), purposefulness (1.9), flexibility (2.1) and preciseness (2.1). These characteristics elicited more favorable ratings than self-confidence (2.4), authority (2.4), spontaneity (2.5), straightforwardness (2.6) and formality (3.1). All characteristics were taken from Andersen (1997), who asked employees of a Danish firm to list traits of Danish company representatives (autostereotyping) and to describe the traits they believe Germans assign to Danes (projected heterostereotyping).

Question twelve tried to ascertain the extent to which the respondents believe the above-mentioned traits to be typical of Danish company representatives ( $1=$ to a very large extent and $6=$ not typical at all): discipline (1.9), tolerance (1.9), hospitality (2.0), flexibility (2.2), punctuality (2.2), purposefulness (2.4), self-confidence (2.6), preciseness (2.8), straightforwardness (2.8), spontaneity (3.0) and formality (4.1). The table 
below allows a comparison of the preference score given to a trait by the respondents with the extent to which they consider this trait to be typical of Danes.

\begin{tabular}{|l|c|c||}
\hline $\begin{array}{l}\text { Traits given preference by Schleswig-Holsteinian } \\
\text { respondents }\end{array}$ & preference score & "typicality" score \\
\hline Hospitality & 1.7 & 2.0 \\
\hline Punctuality & 1.7 & 2.2 \\
\hline Discipline & 1.8 & 1.9 \\
\hline Tolerance & 1.9 & 1.9 \\
\hline Purposefulness & 1.9 & 2.4 \\
\hline Flexibility & 2.1 & 2.2 \\
\hline Preciseness & 2.1 & 2.8 \\
\hline Self-confidence & 2.4 & 2.6 \\
\hline Authority & 2.4 & 3.8 \\
\hline Spontaneity & 2.5 & 3.0 \\
\hline Straightforwardness & 2.6 & 2.8 \\
\hline Formality & 3.1 & 4.1 \\
\hline \hline
\end{tabular}

In the opinion of the respondents, Danish company representatives could be a little more punctual, purposeful, precise, authoritative, spontaneous and formal (a difference of up to 1.4 points).

The results of the survey in Schleswig-Holstein show that the responding companies have a moderately positive attitude to the use of German by their foreign business partners. Apparently, English language use is very well received in the Schleswig-Holsteinian business community. 
They also provide us with information as to what is regarded as most useful: German language knowledge on the part of their foreign business partners or knowledge of German culture. Clearly, the respondents prefer the latter. In addition, they state that they do not put strong qualitative linguistic demands - apart from intelligibility - on their Danish business partners who choose German to communicate with them, and that language/cultural barriers do not really complicate German-Danish business relations. Strictly speaking, they seem to think that these business communications are less frequently impaired through cultural barriers than through language barriers. Nonetheless, the respondents would welcome more written documents, as well as more formal and authoritative behavior on part of their Danish business partners.

Many corporate activities require the use of foreign languages. The need for business oriented foreign language skills has two major sources: strategies relative to buying psychology, and corporate tactics of communicating successfully. Linguistic and cultural adaptation allows nonnative speakers to communicate in a receiver friendly style and to improve the atmosphere. It may help in closing the deal. Ultimately, language choice is made on very practical grounds, namely language knowledge. The command which company representatives should have of a foreign language consists not only of the ability to find the appropriate (technical) word, pronounce/spell it correctly, connect it with other words in a sentence in order to say or write what they mean but also of an awareness of the socio-cultural context of that language. Unfortunately, there is often a basic lack of knowledge of the socio-cultural norms native speakers follow and hence a misunderstanding of these speakers.

\section{The educational implications of the findings of needs analysis studies}

Foreign language users in business settings face many problems entailed by lacking (intercultural) communicative competence. A lacking knowledge of intercultural differences, for instance different communication styles, leads to miscommunication. Teachers of business German should keep such problems realistically before them as they teach and should build remedies into the curriculum. Central to the demanding task of these teachers is the anticipation and ranking of the learners' needs in their (later) careers. Because of the close relationship between 
language and culture (future) users of business German need to develop intercultural sensitivity and competency. They should be aware of the socio-cultural context of language and acquire communicative skills for intercultural professional situations.

How should Danish learners of business German be equipped? According to the feedback from Schleswig-Holsteinian companies, foreign companies with business connections to Germany need knowledge of the economic geography of Germany, of the organizational structure of German companies, of German business culture/conduct and of German mentality. It is of particular interest that, in the opinon of the respondents, cultural proficiency is even more important than language proficiency. Hence, Danish students who study business German need study programmes that help them to achieve intercultural communicative competence relevant to German-Danish business exchanges.

Researchers of foreign language didactics have proposed only a few models and educational tools which weave language competence together with cultural knowledge (Byram 1989, Blom 1991, Beamer 1992, Moureau-Martini 1994, Bowe 1994, Verckens et al. 1998). Blom stresses that the ability to speak a foreign language should be embedded deeply in an understanding of a cultural setting. When preparing Danish future export managers to conduct business negotiations outside the Danish culture, he uses a pedagogical tool with a proven track record, namely a role-play exercise. He tapes student role-plays (simulated complex reallife situations to be mastered in a foreign language such as a discussion between a Danish manager and an agent from abroad). Transcripts of these tape-recorded student role-plays are compared with transcripts of similar communications between two native speakers. Students are not only confronted with their own grammatical, lexical and pragmatic mistakes but also with their culturally inappropriate language behaviour, when they mistakenly transfer Danish cultural norms to the foreign language.

The course in international business writing designed by Verckens et al. (1998) works with three educational tools in order to familiarize students in Belgium, Finland and the United States with the cultural context of language: first, text books on the subject of cross-cultural communication, second, field-research (that is foreign language need analyses) and third, simulation games. As participants in the business 
games, the students must produce written documents in English that are actually sent to other students, who will then respond to them. The problem of cultural adaptation to the receiver is raised during an open discussion in class. Letters are evaluated with a view to establishing business relations outside one's own culture. What is extremely interesting is the fact that need analysis is used as an educational tool by Verckens et al. (1998: 248):

"The field-research component makes students look beyond the wall of the educational institution to find out what goes on in the real world of business with regard to cross-cultural communication. The students, using a questionnaire, are asked to interview a manager who has to communicate internationally in order to perform his/her tasks. The results are used to critically reflect on the general theories, methods, and statements and particular anecdotes that our source books present".

\section{Conclusion}

Before learners of a foreign language for business purposes can obtain access to this foreign language and culture their teachers must know which business-related skills and knowledge learners need. Teaching goals and subjects should be designed to match the learners' needs. The findings of needs analysis studies are very valuable for foreign language teachers who want to develop a curriculum that best suits the needs of their students. Moreover, needs analysis can be used as an educational tool both in language instruction (as Verckens et al. do) and in language teacher training.

The present study described various so far little-investigated qualitative needs. Its purpose was to shed light on one of the factors which create foreign language needs, namely the attitudes of native speakers towards linguistic and cultural adaptation on the part of their non-native communication partners. To educators in foreign language studies, who train (future) foreign language teachers, knowledge of those attitudes is of great importance. Trainees must acquire such specific knowledge from their educators in order to use it in instructional practice themselves. The study dealt with in this paper constitutes only one of the parts of the puzzle that must be fitted together correctly "to get the true picture". It is of paramount importance that as many research techniques as possible are used. It is also of great importance that as many informants as possible 
are interviewed (export managers, foreign business partners, lecturers of international communication, etc.) because informants' statements are subjective and therefore disagreement-prone. In fact, a respondent's claim that a company has foreign language needs originates in his/her attitudes towards the use, acquisition and perfection of foreign languages (Vandermeeren, in press). It must be borne in mind that researchers too have attitudes concerning language needs which inevitably influence their choice of research objectives and their interpretation of the findings. Overall, foreign language skills are regarded as a prerequisite for economic success. Among most language needs researchers there is a consensus about the positive effect of linguistic and cultural adaptation.

\section{References}

Andersen, Anne-Marie 1997: Interkulturelle Wirtschaftskommunikation in Europa: Deutschland - Dänemark. Tostedt: Attikon.

Atteslander, Peter 1993: Methoden der empirischen Sozialforschung. Berlin: de Gruyter.

Beamer, Linda 1992: Learning intercultural communication competence. In Journal of Business Communication 29, 285-303.

Blom, Asger 1994: Ein Unterrichtsprojekt für internationale Verhandlungen. In Bungarten, Theo (ed.) Kommunikationstraining und -trainingsprogramme im wirtschaftlichen Umfeld. Tostedt: Attikon. 9-16.

Bowe, Heather 1994: University courses - linguistics for business. In Bungarten, Theo (ed.) Kommunikationstraining und-trainingsprogramme im wirtschaftlichen Umfeld. Tostedt: Attikon. 41-55.

Byram, Michael 1989: Cultural studies in foreign language education Clevedon et al.: Multilingual Matters.

Dannerer, Monika 1992: Wirtschaftsdeutsch in Ungarn. Eine empirische Studie über Bedarf und Probleme. In Informationen Deutsch als Fremdsprache 19/3, 335-349.

Drochner, Karl-Heinz and Kirchberg, Erika 1987: Zum Bedarf an Fremdsprachenkenntnissen. Statistische Untersuchung anhand von Stellenanzeigen in italienischen Tageszeitungen. In Scuola e lingue moderne 3, 46-58.

Fishman, Joshua A./Cooper, Robert L. 1978: The sociolinguistic foundations of language testing. In Spolsky, Bernard (ed.) Approaches to language testing. Advances in language testing Series 2. Arlington: Center for Applied Linguistics. 31-38.

Francis, June N. P. 1991: When in Rome? The effect of cultural adaptation on intercultural business negotiations. In Journal of International Business Studies 22, 403-428.

Glück, Helmut 1992: Die internationale Stellung des Deutschen auf dem europäischen Arbeitsmarkt. In Kramer, Wolfgang/Weiß, Reinhold (eds) Fremdsprachen in der Wirtschaft. Ein Beitrag zu interkultureller Kompetenz. Köln: Dt. Inst.-Verl. 47-75. 
Grinsted, Annelise 1993: Southern Denmark. In: Hagen, Stephen (ed.) Languages in European business. A regional survey of small \& medium-sized companies. London: CTC Trust. 48-58.

Martin, Jeanette S./Chaney, Lilian H. 1992: Determination of content for a collegiate course in intercultural business communication by three Delphi panels. In Journal of Business Communication 29, 267-284.

Moureau-Martini, Ursula 1994: Interkulturelles Training mit Video. Deutsch für Nachwuchskräfte französischer Exportfirmen. In Bungarten, Theo (ed.) Kommunikationstraining und-trainingsprogramme im wirtschaftlichen Umfeld. Tosted: Attikon. 201208.

Pogner, Karl-Heinz 1999: Discourse community, culture and interaction : on writing by consulting engineers. In Bargiela-Chiappini, Francesca/Nickerson, Catherine (eds) Writing Business: Genres, Media and Discourses. Harlow et al.: Longman. 101-127.

Rasmussen, Gitte 2000: Zur Bedeutung kultureller Unterschiede in interlingualen, interkulturellen Gesprächen. Iudicium.

Reeves, Nigel 1985: Education for exporting capability - languages and market penetration. In The Incorporated Linguist 23/3-4, 147-153.

Schuman, Howard/Presser, Stanley 1981: Questions and answers in attitude surveys. Experiments on question form, wording and context. New York: Academic Press.

Vandermeeren, Sonja 1998: Fremdsprachen in europäischen Unternehmen. Untersuchungen zu Bestand und Bedarf im Geschäftsalltag mit Empfehlungen für Sprachenpolitik und Sprachunterricht. Waldsteinberg: Popp.

Vandermeeren, Sonja 1999: English as a lingua franca in written corporate communication: findings from a European survey. In Bargiela-Chiappini, Francesca/Nickerson, Catherine (eds) Writing Business: Genres, Media and Discourses. Harlow et al.: Longman. 273-291.

Vandermeeren, Sonja (in press) Research on language attitudes. In Ammon, Ulrich et al. (eds) Sociolinguistics. Berlin et al.: de Gruyter.

van Els, Theo et al. 1984: Applied linguistics and the learning and teaching of foreign languages. London et al.: Arnold.

van Hest, Erna/Oud, Maria 1990: Eine Untersuchung der bei der Diagnose und Analyse von Fremdsprachenbedarf in Handel und Industrie verwendeten Techniken. Luxemburg: Kommission der Europäischen Gemeinschaften.

Verckens, Jan P. et al. 1998: The experience of sameness in differences: A course in international business writing. In Niemeier, Susanne et al. (eds.) The Cultural Context in Business Communication. Amsterdam et al.: Benjamins. 247-261.

Verdoodt, Albert/Delbeke, Luc 1983: Belangstelling voor en werkelijke behoeften aan moderne vreemde talen in België. Verslag 2. Een onderzoek naar de algemene behoeften aan talen in bedrijven en overheidsdiensten. Leuven: Centrum voor Mathematische Psychologie en Psychologische Methodologie. 


\title{
Add dimension to your sociological research
}

\section{sociological abstracts}

Comprehensive, cost-effective, timely

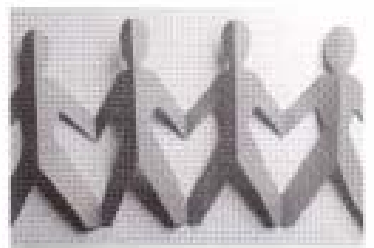

Abstracts of articles, books, and conference papers from nearly 2,500 journals published in 35 countries; citations of relevant dissertations as well as books and other media.

Available in print or electronically through the Internet Database Service from Cambridge Scientific Abstracts (www.csa.com).

Contact sales@csa.com for trial Internet access or a sample issue.

\section{sociological abstracts}

\author{
Published by CSA
}

